\title{
Characterization and Early Age Physical Properties of Ambient Cured Geopolymer Mortar Based on Class C Fly Ash
}

\author{
Ashley Russell Kotwal ${ }^{1)}$, Yoo Jae $\mathrm{Kim}^{1,2), \star}$, Jiong $\mathrm{Hu}^{2)}$, and Vedaraman Sriraman ${ }^{2)}$
}

(Received January 17, 2014, Accepted June 9, 2014, Published online August 5, 2014)

\begin{abstract}
The critical element for sustainable growth in the construction industry is the development of alternative cements. A new technological process called geopolymerization provides an innovative solution, and the presence of aluminum and silicon oxides in fly ash has encouraged its use as a source material. Many previous investigations have involved curing the binder in a heated environment. To reduce energy consumption during the synthesis of geopolymers, the present study investigated the properties of ambient cured geopolymer mortar at early ages. An experimental program was executed to establish a relationship between the activator composition and the properties of geopolymer mortar in fresh and hardened states. Concentrations of sodium hydroxide and sodium silicate were ascertained that are advantageous for constructability and mechanical behavior. Scanning electron microscopy, energy dispersive X-ray spectroscopy and X-ray diffraction techniques were also used to characterize the material. Test results indicate that there is potential for the concrete industry to use fly ash based geopolymer as an alternative to portland cement.
\end{abstract}

Keywords: geopolymer, fly ash, cement, mortar, characterization.

\section{Introduction}

Concrete is the most widely used construction material and the second most consumed resource in the world (Seal et al. 2011). The principal component and binder in concrete is portland cement. To supply the material on such a large scale, the portland cement industry in the United States consumes over 500 petajoules of energy per year (Worrell and Galitsky 2008). The production of portland cement is consequently one of the largest global sources of combustion and chemical process related carbon dioxide emissions, accounting for $5 \%$ of global carbon dioxide production or approximately 1.5 gigatonnes per year (Pearce 1997; Hanle et al. 2011; PCA 2012).

The current trend in the construction industry is leaning more towards sustainable practices every year, making research valuable by providing a means to limit waste and recycle material. The use of recycled materials and byproducts has ecological effects that benefit the

\footnotetext{
${ }^{1)}$ Materials Science, Engineering and Commercialization Program, Department of Engineering Technology, Texas State University, San Marcos, TX 78666, USA.

*Corresponding Author; E-mail: yk10@txstate.edu

${ }^{2)}$ Concrete Industry Management Program, Department of Engineering Technology, Texas State University, San Marcos, TX 78666, USA.

Copyright $($ The Author(s) 2014. This article is published with open access at Springerlink.com
}

environment by lowering energy consumption and saving valuable landfill space while also accrediting new buildings in accordance with Leadership in Energy and Environmental Design standards (USGBC 2005). The use of recycled materials in concrete research has been limited to recycled admixtures, recycled reinforcement fibers and recycled aggregates. The critical element for sustainable growth, however, is the development of alternative cements to replace conventional portland cement (Davidovits 2011).

Fly ash is a term used to describe the fine particulate material precipitated from the stack gases of industrial furnaces that burn solid fuels. Hundreds of millions of tonnes of this byproduct are produced worldwide every year in coal burning power plants. Fly ash was initially used in concrete as an admixture to enhance rheological properties and reduce the alkali aggregate reaction (Mindess and Young 1981). As a pozzolan, fly ash also exhibits cementitious properties when combined with calcium hydroxide. However, fly ash from different sources may have varying effects due to chemical composition (Popovics 1982). Despite the variation, there are many research efforts and industry applications that focus on replacing portland cement with recycled materials such as fly ash.

An alternative method of reducing the use of portland cement is by incorporating fly ash into a new technological process called geopolymerization (Silverstrim et al. 1999). Geopolymers are formed when aluminum and silicon oxides react with a strong alkaline solution. Due to its similarity to natural sources of aluminum and silicon oxides, fly ash can be combined with an alkaline solution to produce new geopolymer binders (Jiang and Roy 1992). Consequently, geopolymer mortar has the potential to become a low cost 
and low emission building material. By applying this new technology, byproducts can be transformed into useful construction materials, and the carbon dioxide from portland cement production can be reduced by as much as $90 \%$ (Davidovits 1994). Like many innovative materials, however, the appropriate practices, properties and applications of geopolymers have not yet been fully determined.

Many investigations of geopolymer synthesis have focused on optimizing the quantity, constituents and concentration of the alkaline activator (Leelathawornsuk 2009; Mustafa et al. 2011; Somna et al. 2011). In search of optimal curing conditions, other studies have investigated the effect of elevated temperatures on polycondensation and hardening (Jaarsveld et al. 2002; Vijai et al. 2010; Guo et al. 2010).

\section{Research Significance}

Although previous investigations have shown that curing geopolymers at elevated temperatures can hasten strength development, the present study was conducted to develop ambient cured geopolymer mortar for practical applications in the construction industry. Additional investigation was also undertaken with regards to the effect of the activator on constructability and early age mechanical behavior.

\section{Experimental Investigation}

The present study experimentally analyzed the effect of the activator composition on the fresh and hardened properties of geopolymer mortar based on Class C fly ash. By developing information, specifically concerning geopolymer mortar composition, the concrete industry can potentially use fly ash based geopolymer as an alternative to portland cement. Concentrations of sodium hydroxide $(\mathrm{NaOH})$ and sodium silicate $\left(\mathrm{Na}_{2} \mathrm{SiO}_{3}\right)$ were manipulated to optimize the constructability and mechanical behavior of geopolymer mortar. The binder content was also varied in relation to the aggregate weight to lower the quantity of chemical constituents.

\subsection{Materials}

\subsubsection{Physical Properties}

Class C fly ash from the Calaveras Power Station in San Antonio, Texas, was used as the primary component of the geopolymer mortar. Limestone sand was the source of fine aggregate, and the activator was composed of $\mathrm{NaOH}$ and $\mathrm{Na}_{2} \mathrm{SiO}_{3}$. The benefit of incorporating $\mathrm{NaOH}$ into geopolymer mixtures is its exothermic capacity as a strong chemical base to react with the source material. The addition of $\mathrm{Na}_{2} \mathrm{SiO}_{3}$ allows the quantity of the mineral component to be reduced, and including it in the mixture is also advantageous for faster hardening of the binder. Table 1 presents the physical properties of the geopolymer constituents.

The specific gravity, density and absorption of the limestone sand were calculated as per ASTM C128, and a sieve analysis was also performed in accordance with ASTM C136 and C33 (ASTM 2006, 2011, 2012). Table 2 presents the physical properties of the limestone sand, and Fig. 1 illustrates the results of the sieve analysis.

\subsubsection{Characterization}

Scanning electron microscopy and energy dispersive X-ray spectroscopy were performed with a FEI Helios Nanolab 400. For characterization of the geopolymer, $50 \mathrm{~mm}$ cube specimens of paste were cast with a $\mathrm{NaOH}$ to fly ash ratio of 0.10 and $\mathrm{Na}_{2} \mathrm{SiO}_{3}$ to fly ash ratio of 0.10 by mass. Samples were taken from hardened specimens after 28 days to reduce their size for preparation and examination. The moisture content of the samples was lowered by placing them in an oven at $110^{\circ} \mathrm{C}$ for $1 \mathrm{~h}$. Manual polishing was

Table 1 Physical properties of geopolymer constituents.

\begin{tabular}{|c|c|c|c|c|}
\hline Material & Provider & Chemical composition & Specific gravity & Retained on \#325 sieve \\
\hline \multirow[t]{3}{*}{ Class C fly ash } & \multirow{3}{*}{$\begin{array}{l}\text { Boral Material } \\
\text { Technologies }\end{array}$} & $>80 \% \mathrm{CaAl}_{2} \mathrm{Si}_{2} \mathrm{O}_{8}$ & \multirow[t]{3}{*}{2.65} & \multirow[t]{3}{*}{$11 \%$} \\
\hline & & $<15 \% \mathrm{Fe}_{2} \mathrm{MgO}_{4}$ & & \\
\hline & & $<5 \% \mathrm{Na}_{2} \mathrm{~K}_{2} \mathrm{SO}_{5}$ & & \\
\hline \multirow[t]{2}{*}{$\mathrm{NaOH}$ pellets } & \multirow[t]{2}{*}{ Fisher Scientific } & $>95 \% \mathrm{NaOH}$ & \multirow[t]{2}{*}{2.13} & \multirow[t]{2}{*}{-} \\
\hline & & $<3 \% \mathrm{Na}_{2} \mathrm{CO}_{3}$ & & \\
\hline \multirow[t]{3}{*}{$\mathrm{Na}_{2} \mathrm{SiO}_{3}$ solution } & \multirow[t]{3}{*}{ PQ Corporation } & $14.7 \% \mathrm{Na}_{2} \mathrm{O}$ & \multirow[t]{3}{*}{1.53} & \multirow[t]{3}{*}{-} \\
\hline & & $29.4 \% \mathrm{SiO}_{2}$ & & \\
\hline & & $55.9 \% \mathrm{H}_{2} \mathrm{O}$ & & \\
\hline
\end{tabular}

Table 2 Physical properties of limestone sand.

\begin{tabular}{c|c|c|c|c}
\hline Material & Oven dry specific gravity & $\begin{array}{c}\text { Saturated surface dry } \\
\text { specific gravity }\end{array}$ & Absorption \\
\hline \hline Limestone sand & 2.46 & 2.57 & $4.6 \%$ \\
\hline
\end{tabular}




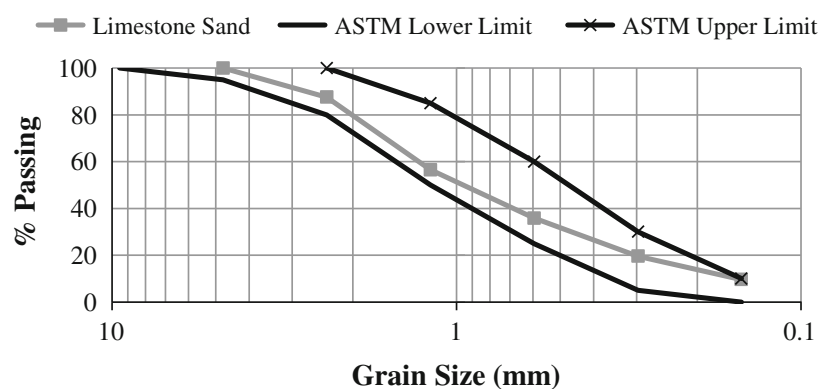

Fig. 1 Sieve analysis of limestone sand.

then performed using 1,200 grit and 2,000 grit silicon carbide paper. Scratches caused from polishing were reduced by switching to the finer abrasive and rotating the samples $90^{\circ}$ for each abrasive size. Finally, samples were mounted on a stage for examination using carbon tape.

The scanning electron microscope images presented in Fig. 2 depict the characteristic morphology of the original Class $\mathrm{C}$ fly ash and the product of geopolymerization. The fly ash consisted of spherical microparticles of various sizes. Changes in morphology were observed as a consequence of activation and ambient curing.

According to the ASTM C618 test report received from the supplier, the primary components of the fly ash were silicon oxide, aluminum oxide and calcium oxide (ASTM 2012). The chemical analysis of the fly ash and geopolymer are shown in Table 3. The analysis confirms the ASTM C618 chemical test results with oxygen, aluminum, silicon and calcium being the principal elements. Additionally, a larger amount of sodium was measured in the geopolymer cement after activation due to the composition of the activator.

A Bruker D8 Focus was used for measuring the X-ray diffraction pattern of the geopolymer cement. Samples were taken from hardened specimens after 28 days and ground to a fine powder using a mortar and pestle. A thin and level layer of powder was then placed on the stage for determination of the crystalline structure. Figure 3 shows the X-ray diffraction pattern of the geopolymer cement. The main
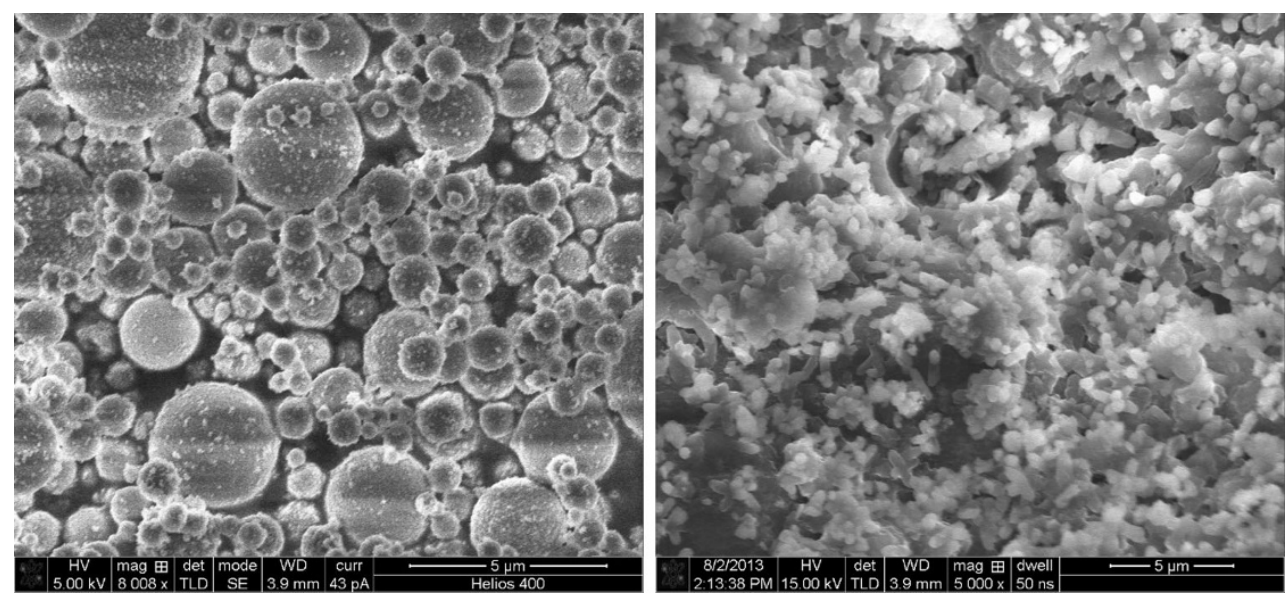

Fig. 2 Scanning electron microscope images of fly ash (left) and geopolymer (right).

Table 3 Chemical analysis of fly ash and geopolymer.

\begin{tabular}{c|c|c|c|c}
\hline \multirow{2}{*}{ Element } & \multicolumn{2}{|c|}{ Fly ash } & \multicolumn{2}{c}{ Geopolymer } \\
\cline { 2 - 5 } & Weight (\%) & Atomic (\%) & Weight (\%) & Atomic (\%) \\
\hline \hline $\mathrm{O}$ & 43.98 & 62.06 & 43.89 & 14.13 \\
\hline $\mathrm{Na}$ & 1.71 & 1.68 & 1.61 & 1.43 \\
\hline $\mathrm{Mg}$ & 2.67 & 2.48 & 7.10 & 5.68 \\
\hline $\mathrm{Al}$ & 9.64 & 8.07 & 11.14 & 8.55 \\
\hline $\mathrm{Si}$ & 10.48 & 8.42 & 0.82 & 0.57 \\
\hline $\mathrm{P}$ & 1.19 & 0.86 & 0.62 & 0.42 \\
\hline $\mathrm{S}$ & 1.05 & 0.74 & 0.31 & 0.17 \\
\hline $\mathrm{K}$ & 0.32 & 0.19 & 15.35 & 8.26 \\
\hline $\mathrm{Ca}$ & 23.21 & 13.07 & 1.05 & 0.47 \\
\hline $\mathrm{Ti}$ & 1.47 & 0.69 & 3.06 & 1.18 \\
\hline
\end{tabular}


crystalline component of the binder was $\mathrm{SiO}_{2}$, which is characterized by the Bragg peak at $26.6^{\circ}$. A large portion of the structure was amorphous, which resulted in a broad diffuse halo rather than sharp peaks. The slight increase in intensity from $20^{\circ}$ to $40^{\circ}$ is characteristic of the amorphous geopolymer matrix.

\subsection{Specimens}

To determine the effects of activator composition and geopolymer content on physical properties, geopolymer mortar was mixed and cast into $50 \mathrm{~mm}$ cube specimens. Concentrations of $\mathrm{NaOH}$ and $\mathrm{Na}_{2} \mathrm{SiO}_{3}$ were manipulated in

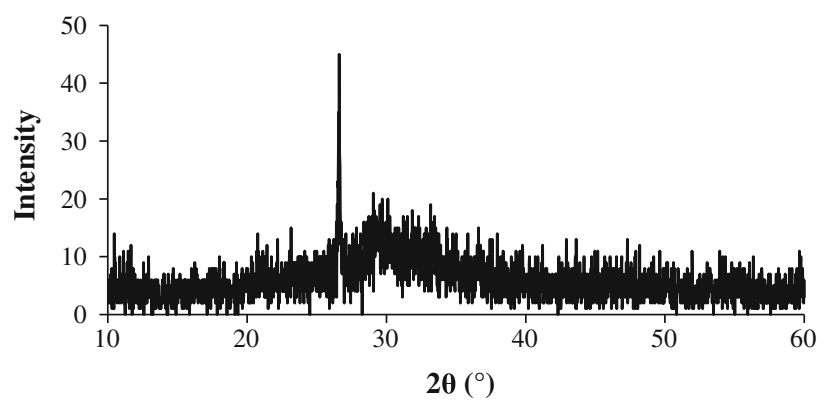

Fig. 3 X-ray diffraction pattern of geopolymer. mixes \#1 through \#16 to optimize the constructability and mechanical behavior of geopolymer mortar. After determining the optimum activator composition, the binder content was also varied in relation to the aggregate weight in mixes \#17 through \#20 to lower the quantity of chemical constituents. Table 4 presents the composition of the mix designs. An $\mathrm{H}_{2} \mathrm{O}$ to fly ash ratio of 0.5 remained constant for all geopolymer mortar mixtures. $\mathrm{H}_{2} \mathrm{O}$ content of the $\mathrm{Na}_{2} \mathrm{SiO}_{3}$ solution was included in the ratio and accounted for during mix design calculations.

\subsection{Procedures}

\subsubsection{Mixing, Casting and Curing}

The materials were stored in sealed containers in a laboratory setting at approximately $23 \pm 2{ }^{\circ} \mathrm{C}$. Prior to beginning the mixing procedure, each component was measured as per the mix design specification. First, the fly ash and limestone sand were dry mixed manually for $1 \mathrm{~min}$, and then the $\mathrm{H}_{2} \mathrm{O}$ and $\mathrm{Na}_{2} \mathrm{SiO}_{3}$ solution were added and mixed for 2 min. Finally, the $\mathrm{NaOH}$ pellets were incorporated, and the geopolymer mortar was mixed manually for an additional $10 \mathrm{~min}$. This mixing procedure was performed for mixes \#1 through \#16 and was based on previous investigations. An 18.9 L planetary mixer was used for mixes \#17 through \#20

Table 4 Geopolymer mortar mix designs.

\begin{tabular}{|c|c|c|c|c|c|c|c|c|}
\hline$\#$ & $\begin{array}{l}\mathrm{NaOH}: f l y \\
\text { ratio ash }\end{array}$ & $\begin{array}{l}\mathrm{Na}_{2} \mathrm{SiO}_{3} \text { :fly } \\
\text { ash ratio }\end{array}$ & $\begin{array}{l}\text { Sand:fly ash } \\
\text { ratio }\end{array}$ & $\begin{array}{l}\text { Fly ash } \\
\left(\mathrm{kg} / \mathrm{m}^{3}\right)\end{array}$ & $\begin{array}{c}\text { Limestone } \\
\text { sand }\left(\mathrm{kg} / \mathrm{m}^{3}\right)\end{array}$ & $\mathrm{H}_{2} \mathrm{O}\left(\mathrm{kg} / \mathrm{m}^{3}\right)$ & $\begin{array}{c}\mathrm{NaOH} \text { pellets } \\
\left(\mathrm{kg} / \mathrm{m}^{3}\right)\end{array}$ & $\begin{array}{c}\mathrm{Na}_{2} \mathrm{SiO}_{3} \\
\text { solution } \\
\left(\mathrm{kg} / \mathrm{m}^{3}\right)\end{array}$ \\
\hline 1 & 0.050 & 0.025 & 1.0 & 720 & 720 & 337 & 36 & 41 \\
\hline 2 & 0.050 & 0.050 & 1.0 & 720 & 720 & 314 & 36 & 82 \\
\hline 3 & 0.050 & 0.075 & 1.0 & 720 & 720 & 292 & 36 & 122 \\
\hline 4 & 0.050 & 0.100 & 1.0 & 720 & 720 & 269 & 36 & 163 \\
\hline 5 & 0.075 & 0.025 & 1.0 & 720 & 720 & 337 & 54 & 41 \\
\hline 6 & 0.075 & 0.050 & 1.0 & 720 & 720 & 314 & 54 & 82 \\
\hline 7 & 0.075 & 0.075 & 1.0 & 720 & 720 & 292 & 54 & 122 \\
\hline 8 & 0.075 & 0.100 & 1.0 & 720 & 720 & 269 & 54 & 163 \\
\hline 9 & 0.100 & 0.025 & 1.0 & 720 & 720 & 337 & 72 & 41 \\
\hline 10 & 0.100 & 0.050 & 1.0 & 720 & 720 & 314 & 72 & 82 \\
\hline 11 & 0.100 & 0.075 & 1.0 & 720 & 720 & 292 & 72 & 122 \\
\hline 12 & 0.100 & 0.100 & 1.0 & 720 & 720 & 269 & 72 & 163 \\
\hline 13 & 0.125 & 0.025 & 1.0 & 720 & 720 & 337 & 90 & 41 \\
\hline 14 & 0.125 & 0.050 & 1.0 & 720 & 720 & 314 & 90 & 82 \\
\hline 15 & 0.125 & 0.075 & 1.0 & 720 & 720 & 292 & 90 & 122 \\
\hline 16 & 0.125 & 0.100 & 1.0 & 720 & 720 & 269 & 90 & 163 \\
\hline 17 & 0.100 & 0.100 & 1.5 & 630 & 945 & 235 & 63 & 143 \\
\hline 18 & 0.100 & 0.100 & 2.0 & 560 & 1,120 & 209 & 56 & 127 \\
\hline 19 & 0.100 & 0.100 & 2.5 & 500 & 1,250 & 187 & 50 & 113 \\
\hline 20 & 0.100 & 0.100 & 3.0 & 450 & 1,350 & 168 & 45 & 102 \\
\hline
\end{tabular}


with a slightly different process. First, the fly ash and limestone sand were dry mixed for $30 \mathrm{~s}$. Then, the $\mathrm{H}_{2} \mathrm{O}$, $\mathrm{Na}_{2} \mathrm{SiO}_{3}$ solution and $\mathrm{NaOH}$ pellets were mixed together in a separate container prior to adding them to the mixture. Finally, the constituents were mixed mechanically for an additional $5 \mathrm{~min}$. The fresh geopolymer mortar was cast into $50 \mathrm{~mm}$ cube and $25 \times 25 \times 285 \mathrm{~mm}$ prism specimens then subjected to external vibration for $1 \mathrm{~min}$ if required in accordance with ASTM C109 (ASTM 2011). Specimens were sealed with plastic wrap, stored in ambient conditions and demolded immediately before measuring hardened physical properties.

\subsubsection{Fresh Property Tests}

The temperature of the freshly mixed geopolymer mortar was measured with a digital stem type thermometer in accordance with ASTM C1064, a flow table was used to measure the flow in accordance with ASTM C1437, and digital scales were used to measure mass in order to calculate density (ASTM 1437 2007; ASTM 1064 2011).

\subsubsection{Hardened Property Tests}

Compressive testing was performed with a Test Mark CM400 compressive machine in accordance with ASTM C109. Digital scales and calipers were also used to measure mass and dimensions in order to calculate the density of hardened geopolymer mortar specimens.

\subsection{Analytical Techniques}

The data was subjected to an analysis of variance (ANOVA) using SPSS statistical software. This method establishes the magnitude of the total variation in the results and distinguishes the random variation from the contribution of each variable. A conventional level of significance $(p<0.05)$ was used for the statistical analysis.

\section{Experimental Results}

The fresh and hardened properties measured for each geopolymer mortar mix design are presented in Tables 5 and 6 , respectively.

\subsection{Temperature}

The properties of fresh geopolymer mortar are considered to be important due to the relation they have with the workability of the material. Figures 4 and 5 show the test results for temperature, which ranged from 32 to $54{ }^{\circ} \mathrm{C}$. The temperature increased with higher levels of $\mathrm{NaOH}$ and $\mathrm{Na}_{2} \mathrm{SiO}_{3}$ due to the caustic nature of the strong chemical

Table 5 Fresh properties of geopolymer mortar.

\begin{tabular}{|c|c|c|c|c|c|c|}
\hline$\#$ & $\mathrm{NaOH}: f l y$ ash ratio & $\begin{array}{c}\mathrm{Na}_{2} \mathrm{SiO}_{3} \text { :fly ash } \\
\text { ratio } \\
\end{array}$ & Sand:fly ash ratio & Temperature $\left({ }^{\circ} \mathrm{C}\right)$ & Flow $(\%)$ & $\begin{array}{c}\text { Fresh density } \\
\left(\mathrm{kg} / \mathrm{m}^{3}\right)\end{array}$ \\
\hline 1 & 0.050 & 0.025 & 1.0 & 32 & $>150$ & 2,210 \\
\hline 2 & 0.050 & 0.050 & 1.0 & 33 & $>150$ & 2,142 \\
\hline 3 & 0.050 & 0.075 & 1.0 & 34 & $>150$ & 2,144 \\
\hline 4 & 0.050 & 0.100 & 1.0 & 37 & $>150$ & 2,150 \\
\hline 5 & 0.075 & 0.025 & 1.0 & 35 & $>150$ & 2,177 \\
\hline 6 & 0.075 & 0.050 & 1.0 & 37 & $>150$ & 2,182 \\
\hline 7 & 0.075 & 0.075 & 1.0 & 39 & $>150$ & 2,179 \\
\hline 8 & 0.075 & 0.100 & 1.0 & 41 & 132 & 2,145 \\
\hline 9 & 0.100 & 0.025 & 1.0 & 43 & $>150$ & 2,178 \\
\hline 10 & 0.100 & 0.050 & 1.0 & 42 & $>150$ & 2,230 \\
\hline 11 & 0.100 & 0.075 & 1.0 & 44 & $>150$ & 2,197 \\
\hline 12 & 0.100 & 0.100 & 1.0 & 46 & 120 & 2,193 \\
\hline 13 & 0.125 & 0.025 & 1.0 & 53 & 134 & 2,148 \\
\hline 14 & 0.125 & 0.050 & 1.0 & 54 & 128 & 2,133 \\
\hline 15 & 0.125 & 0.075 & 1.0 & 49 & 112 & 2,164 \\
\hline 16 & 0.125 & 0.100 & 1.0 & 52 & 94 & 2,156 \\
\hline 17 & 0.100 & 0.100 & 1.5 & 38 & 107 & 2,084 \\
\hline 18 & 0.100 & 0.100 & 2.0 & 37 & 83 & 2,129 \\
\hline 19 & 0.100 & 0.100 & 2.5 & 37 & 57 & 2,182 \\
\hline 20 & 0.100 & 0.100 & 3.0 & 36 & 32 & 2,254 \\
\hline
\end{tabular}


Table 6 Hardened properties of geopolymer mortar.

\begin{tabular}{|c|c|c|c|c|c|}
\hline$\#$ & $\mathrm{NaOH}$ :fly ash ratio & $\mathrm{Na}_{2} \mathrm{SiO}_{3}$ :fly ash ratio & Sand:fly ash ratio & $\begin{array}{l}7 \text { day hardened } \\
\text { density }\left(\mathrm{kg} / \mathrm{m}^{3}\right)\end{array}$ & $\begin{array}{c}7 \text { day compressive } \\
\text { strength }(\mathrm{MPa})\end{array}$ \\
\hline 1 & 0.050 & 0.025 & 1.0 & 2,117 & 5 \\
\hline 2 & 0.050 & 0.050 & 1.0 & 2,113 & 8 \\
\hline 3 & 0.050 & 0.075 & 1.0 & 2,121 & 10 \\
\hline 4 & 0.050 & 0.100 & 1.0 & 2,134 & 20 \\
\hline 5 & 0.075 & 0.025 & 1.0 & 2,161 & 16 \\
\hline 6 & 0.075 & 0.050 & 1.0 & 2,161 & 26 \\
\hline 7 & 0.075 & 0.075 & 1.0 & 2,158 & 32 \\
\hline 8 & 0.075 & 0.100 & 1.0 & 2,138 & 32 \\
\hline 9 & 0.100 & 0.025 & 1.0 & 2,174 & 26 \\
\hline 10 & 0.100 & 0.050 & 1.0 & 2,167 & 32 \\
\hline 11 & 0.100 & 0.075 & 1.0 & 2,187 & 35 \\
\hline 12 & 0.100 & 0.100 & 1.0 & 2,186 & 40 \\
\hline 13 & 0.125 & 0.025 & 1.0 & 2,119 & 23 \\
\hline 14 & 0.125 & 0.050 & 1.0 & 2,136 & 25 \\
\hline 15 & 0.125 & 0.075 & 1.0 & 2,151 & 27 \\
\hline 16 & 0.125 & 0.100 & 1.0 & 2,138 & 33 \\
\hline 17 & 0.100 & 0.100 & 1.5 & 2,041 & 32 \\
\hline 18 & 0.100 & 0.100 & 2.0 & 2,091 & 39 \\
\hline 19 & 0.100 & 0.100 & 2.5 & 2,136 & 36 \\
\hline 20 & 0.100 & 0.100 & 3.0 & 2,220 & 36 \\
\hline
\end{tabular}

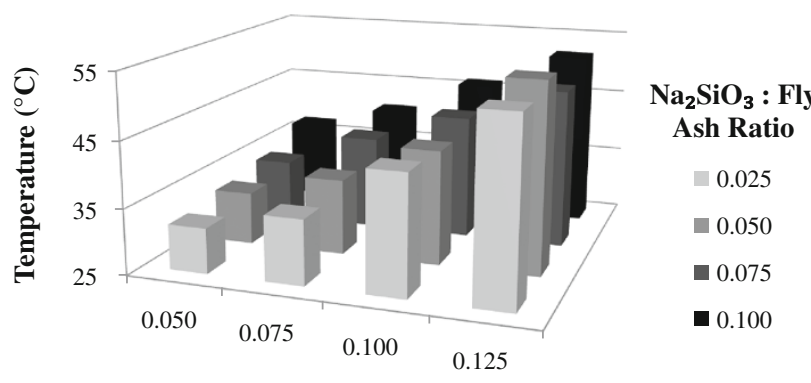

$\mathrm{NaOH}$ : Fly Ash Ratio

Fig. 4 Effect of sodium silicate and sodium hydroxide on temperature.

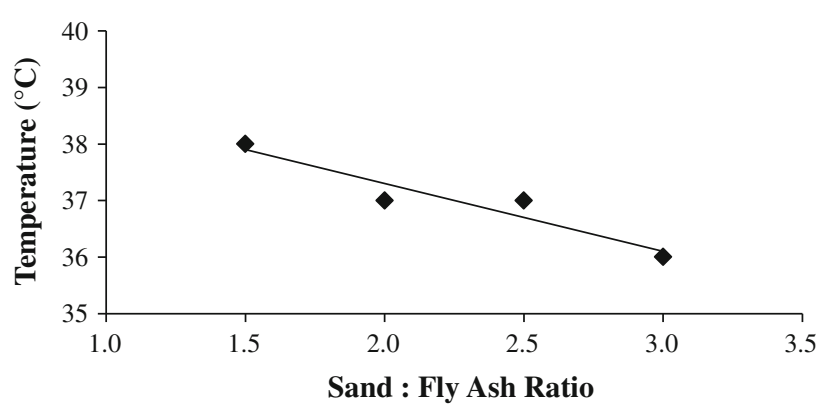

Fig. 5 Effect of fine aggregate content on temperature.

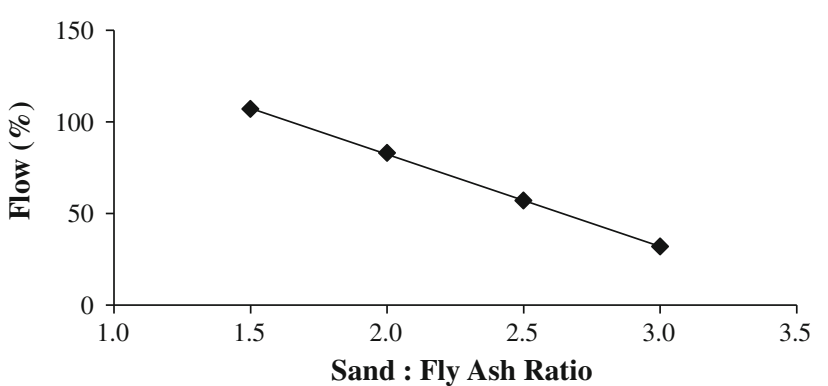

Fig. 6 Effect of fine aggregate content on flow.

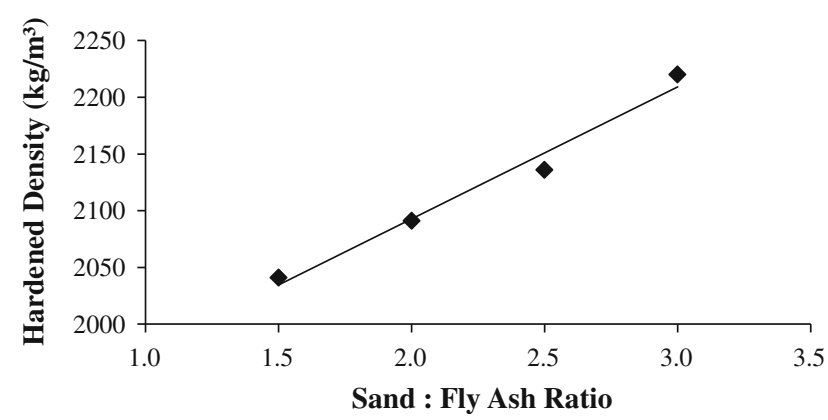

Fig. 7 Effect of fine aggregate content on hardened density. 


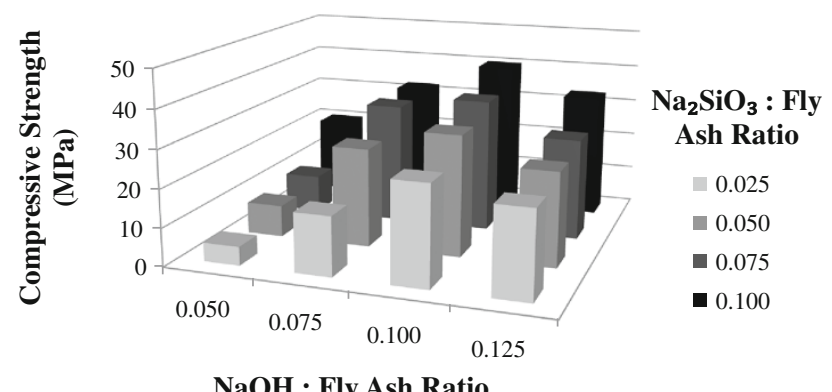

$\mathrm{NaOH}$ : Fly Ash Ratio

Fig. 8 Effect of sodium silicate and sodium hydroxide on 7 day compressive strength.

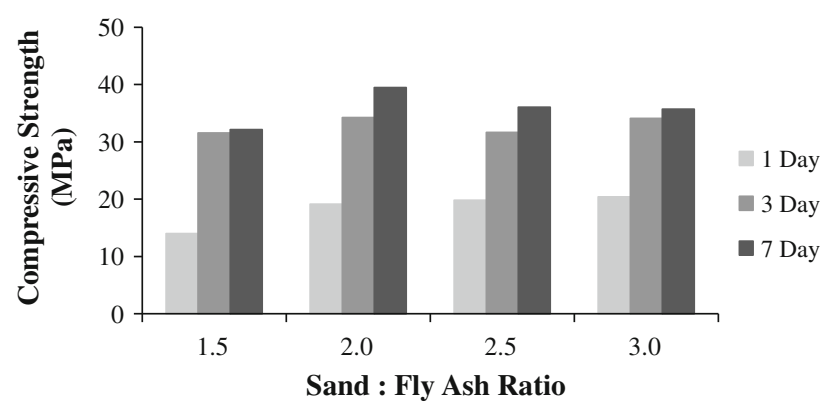

Fig. 9 Effect of age and fine aggregate content on compressive strength.

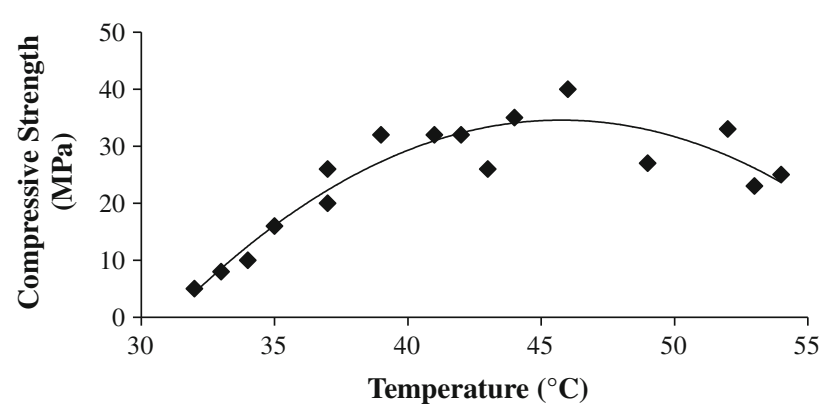

Fig. 10 Correlation of fresh temperature and 7 day compressive strength.

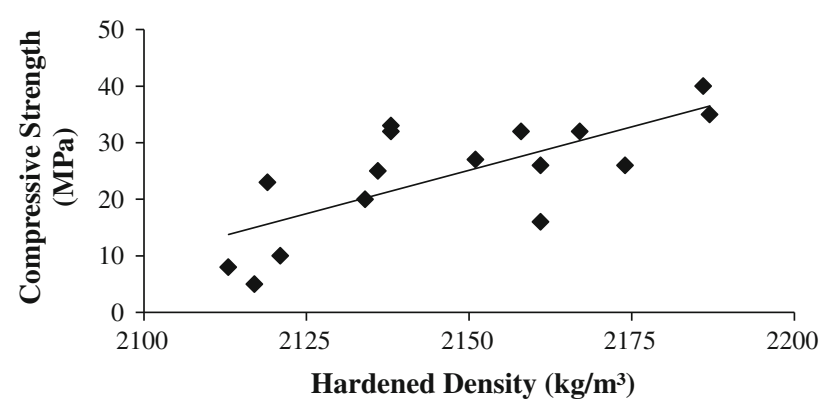

Fig. 11 Correlation of 7 day hardened density and compressive strength.

base. However, the temperature lowered gradually as fine aggregate content increased, thereby improving the ability to handle the material.

\subsection{Flow}

Flow was measured as the resulting percentage increase in average base diameter of the fresh geopolymer mortar.
Lower levels of $\mathrm{NaOH}$ and $\mathrm{Na}_{2} \mathrm{SiO}_{3}$ produced mixtures with flow greater than $150 \%$. However, the flow decreased as a result of increasing the $\mathrm{NaOH}$ component. Additional $\mathrm{OH}^{-}$ ions accelerated dissolution, causing the matrix to precipitate earlier. Higher viscosity and rapid formation of the binder also resulted from increasing the $\mathrm{Na}_{2} \mathrm{SiO}_{3}$ component. Figure 6 shows the effect of geopolymer content on flow, which decreased gradually as a consequence of increasing the fine aggregate content.

\subsection{Density}

Density should also be considered when investigating mechanical behavior, because it affects the material's elastic modulus. The fresh density ranged from 2,084 to $2,254 \mathrm{~kg} / \mathrm{m}^{3}$, and the hardened density ranged from 2,041 to $2,220 \mathrm{~kg} / \mathrm{m}^{3}$. No substantial variation in density was measured due to specimen age or manipulation of the activator components. However, higher quantities of fine aggregate corresponded to denser geopolymer mortar as per Fig. 7.

\subsection{Compressive Strength}

The compressive strength of geopolymer mortar is commonly considered to be its most important characteristic, although in some cases, the bond strength or flexural strength may be more critical. Figures 8, 9, 10 and 11 illustrate the test results for compressive strength as well as its correlation with temperature and hardened density. The 7 day compressive strength ranged from 5 to $40 \mathrm{MPa}$. Strength increased gradually as a result of incorporating additional $\mathrm{NaOH}$ and $\mathrm{Na}_{2} \mathrm{SiO}_{3}$. However, increasing the $\mathrm{NaOH}$ to fly ash ratio only resulted in higher compressive strength up to the 0.10 level. Excessive $\mathrm{OH}-$ ions accelerated dissolution but decreased polycondensation, causing the binder to precipitate early and lose strength.

It is also important to consider specimen age to determine the mechanical behavior of geopolymer mortar over time. The strength was acquired gradually during the first 7 days of geopolymer formation. Only a slight increase in compressive strength was measured from 3 to 7 days. Minimal variation in strength was also measured as a result of increasing the fine aggregate content.

The correlation of temperature and compressive strength indicates that strength improved as the temperature of fresh geopolymer mortar increased. However, excessive $\mathrm{NaOH}$ raised the temperature to over $50{ }^{\circ} \mathrm{C}$ and weakened the matrix.

The correlation of hardened density and compressive strength for geopolymer mortar is also typical of mortar based on portland cement. Accordingly, higher strengths are often characteristic of denser material.

The ANOVA for compressive strength is presented in Table 7. Results indicate that the effects of $\mathrm{NaOH}$ and $\mathrm{Na}_{2} \mathrm{SiO}_{3}$ on compressive strength were statistically significant $(p<0.01)$, signifying that the activator components improved dissolution and polycondensation of the source 
Table 7 Analysis of variance for compressive strength.

\begin{tabular}{c|c|c|c|c|c}
\hline Source & Sum of squares & Degrees of freedom & Mean squares & F ratio & $p$ (significance) \\
\hline \hline $\mathrm{NaOH}$ :fly ash ratio & $3,271.01$ & 3 & $1,090.34$ & 196.48 & $<0.01$ \\
\hline $\mathrm{Na}_{2} \mathrm{SiO}_{3}$ :fly ash ratio & $1,252.84$ & 3 & 417.61 & 75.25 & $<0.01$ \\
\hline $\mathrm{NaOH} \times \mathrm{Na}_{2} \mathrm{SiO}_{3}$ & 182.93 & 9 & 20.33 & 3.66 & $<0.01$ \\
\hline Error & 177.58 & 32 & 5.55 & - & - \\
\hline Total & $4,884.36$ & 47 & - & - & - \\
\hline
\end{tabular}

material. Manipulated variables interact if the effect of one of the variables differs depending on the level of the other variable. An interaction effect between the variation sources on compressive strength was also found to be significant $(p<0.01)$, meaning that for each level of $\mathrm{NaOH}$, variations in strength were measured for every increment of the $\mathrm{Na}_{2} \mathrm{SiO}_{3}$ component.

\section{Summary and Conclusions}

An experimental program was executed to evaluate the effect of the activator composition and fine aggregate content on the fresh and hardened properties of geopolymer mortar. Based on the mix design parameters established within the study, concentrations of $\mathrm{NaOH}$ and $\mathrm{Na}_{2} \mathrm{SiO}_{3}$ were ascertained that are advantageous for constructability and early age mechanical behavior.

The temperature of freshly mixed geopolymer mortar increased with higher levels of $\mathrm{NaOH}$ and $\mathrm{Na}_{2} \mathrm{SiO}_{3}$ due to the caustic nature of the strong chemical base. However, flow decreased as a result of increasing the $\mathrm{NaOH}$ component. Higher viscosity and rapid formation of the binder also resulted from increasing the quantity of $\mathrm{Na}_{2} \mathrm{SiO}_{3}$. The constructability of the material was favorable, as it could be molded by hand without difficulty.

Adequate strength was developed by curing the geopolymer mortar in ambient conditions. The strength of hardened specimens increased as a result of incorporating additional $\mathrm{NaOH}$ and $\mathrm{Na}_{2} \mathrm{SiO}_{3}$. Excessive $\mathrm{OH}^{-}$ions accelerated dissolution but decreased polycondensation, causing the binder to precipitate early and lose strength. Based on the parameters of the geopolymer mortar mix design, the optimum $\mathrm{NaOH}$ to fly ash ratio was 0.10 and $\mathrm{Na}_{2} \mathrm{SiO}_{3}$ to fly ash ratio was 0.10 . The strength of the optimum geopolymer mortar mixture was $40 \mathrm{MPa}$ after aging 7 days, indicating that there is potential for the concrete industry to use fly ash based geopolymer as an alternative to portland cement.

Based on these conclusions, there is a need to investigate the long term properties to determine if geopolymer mortar can be applied in structural building applications. Additionally, a microstructural analysis is warranted in order to further optimize the composition of the alkaline activator. An experimental study should also be executed to evaluate the application of ambient cured geopolymers in concrete mixtures.

\section{Open Access}

This article is distributed under the terms of the Creative Commons Attribution License which permits any use, distribution, and reproduction in any medium, provided the original author(s) and the source are credited.

\section{References}

ASTM C1064 (2011). Standard test method for temperature of freshly mixed hydraulic-cement concrete. West Conshohocken, PA: ASTM International.

ASTM C1437 (2007). Standard test method for flow of hydraulic cement mortar. West Conshohocken, PA: ASTM International.

ASTM C136 (2006). Standard test method for sieve analysis of fine and coarse aggregates. West Conshohocken, PA: ASTM International.

ASTM C33 (2011). Standard specification for concrete aggregates. West Conshohocken, PA: ASTM International.

ASTM C109 (2011). Standard test method for compressive strength of hydraulic cement mortars. West Conshohocken, PA: ASTM International.

ASTM C128 (2012). Standard test method for density, relative density (specific gravity) and absorption of fine aggregate. West Conshohocken, PA: ASTM International.

ASTM C618 (2012). Standard specification for coal fly ash and raw or calcined natural pozzolan for use in concrete. West Conshohocken, PA: ASTM International.

Davidovits, J. (1994). Global warming impact on the cement and aggregates industries. World Resource Review, 6(2), 263-278.

Davidovits, J. (2011). Geopolymer chemistry \& applications (3rd ed.). Saint-Quentin: Institut Geopolymere.

Guo, X., Shi, H., \& Dick, W. A. (2010). Compressive strength and microstructural characteristics of class $\mathrm{C}$ fly ash geopolymer. Cement \& Concrete Composites, 32, 142-147.

Hanle, L. J., Jayaraman, K. R., \& Smith, J. S. (2011). CO2 emissions profile of the U.S. cement industry. Washington, DC: United States Environmental Protection Agency.

Jaarsveld, J., Deventer, J., \& Lukey, G. (2002). The effect of composition and temperature on the properties of fly ashand kaolinite-based geopolymers. Chemical Engineering Journal, 89, 63-73.

Jiang, W., \& Roy, D. M. (1992). Hydrothermal processing of new fly ash cement. American Ceramic Society Bulletin, 71(4), 642-647. 
Leelathawornsuk, Y. (2009). The role of sodium hydroxide concentration in fly ash-based geopolymer. Bangkok, Thailand: Kasetsart University.

Mindess, S., \& Young, J. F. (1981). Concrete. Englewood Cliffs, NJ: Prentice Hall.

Mustafa, A. M., Kamarudin, H., Omar, A. K., Norazian, M. N., Ruzaidi, C. M., \& Rafiza, A. R. (2011). The effect of alkaline activator ratio on the compressive strength of fly ash-based geopolymers. Australian Journal of Basic and Applied Sciences, 5(9), 1916-1922.

PCA (2012). Green in practice 102-concrete, cement and CO2. Retrieved from Portland Cement Association: www.concretethinker.com/papers.aspx?docid=312.

Pearce, F. (1997). The concrete jungle overheats. New Scientist, 155(2091), 14.

Popovics, S. (1982). Fundamentals of portland cement concrete: A quantitative approach. New York, NY: Wiley.

Seal, S., Hench, L. L., Moorthy, S. B., Reid, D., \& Karakoti, A. (2011). United States of America Patent No. US 2011/0112272 A1.
Silverstrim, T., Martin, J., \& Rostami, H. (1999). Geopolymeric fly ash cement. In J. Davidovits, R. Davidovits \& C. James (Eds.), Geopolymer international conference (pp. 107-108). Saint-Quentin: Institute Geopolymere.

Somna, K., Jaturapitakkul, C., Kajitvichyanukul, P., \& Chindaprasirt, P. (2011). NaOH-activated ground fly ash geopolymer cured at ambient temperature. Fuel, 90, 2118-2124.

USGBC. (2005). LEED for new construction \& major renovations. Retrieved from United States Green Building Council:

www.usgbc.org/ShowFile.aspx?DocumentID=1095.

Vijai, K., Kumutha, R., \& Vishnuram, B. G. (2010). Effect of types of curing on strength of geopolymer concrete. International Journal of the Physical Sciences, 5(9), 1419-1423.

Worrell, E., \& Galitsky, C. (2008). Energy efficiency improvement and cost saving opportunities for cement making. Washington, DC: Environmental Protection Agency. 